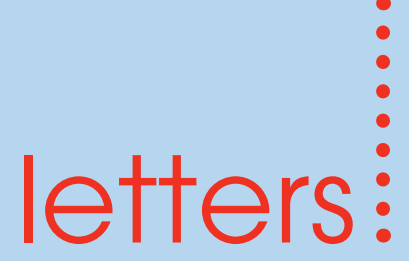

\title{
Battle of the books
}

I am writing this in response to your review of Essential guide to dental nursing (autumn 06 page 18). I bought this guide, which is published by PasTest, some months ago as a reference whilst studying towards my National Certificate in Dental Nursing. Within an hour of receipt of this book I had found a list of errors in it! I was shocked to discover that it was actually written by qualified dental nurses who TEACH this subject!

A list of the errors I found:

\section{Page 116 Figure 6.2}

1. Upper Anterior Teeth

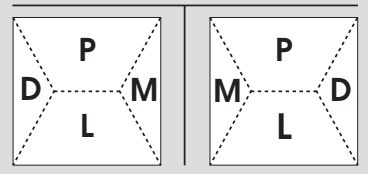

Should be:

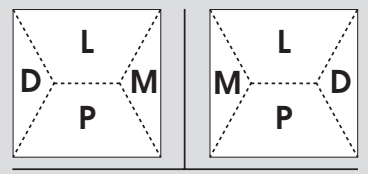

2. Upper Posterior Teeth

\begin{tabular}{|c|c|}
\hline $\mathbf{P}$ & $\mathbf{P}$ \\
\hline $\begin{array}{lll} & \\
& \text { B }\end{array}$ & $\begin{array}{ll}\text { M } \\
\end{array}$ \\
\hline
\end{tabular}

Should be:

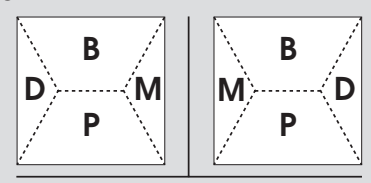

Page 118 Table 6.5 Standard notations for dental charting 3. A recently extracted tooth is charted as:

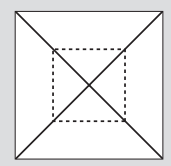

Not:

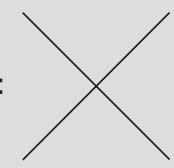

4. A tooth to be extracted is charted as:

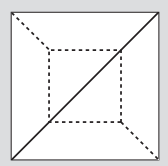

Not:

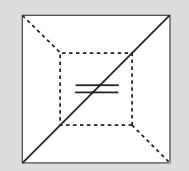

5. A missing tooth is charted as:

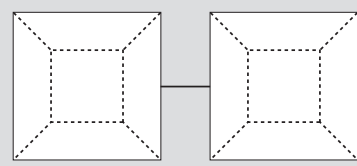

Not:

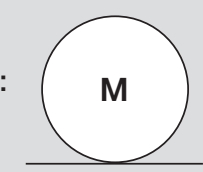

The NEBDN does an excellent booklet on standard charting terms.

6. Page 119 Table 6.7 The FDI System. Does the patient have a LL9 supernumerary tooth or is this an error? No reference is made to this.

\section{Page 120 Table 6.9}

The FDI System of numbering deciduous teeth. Shown as:

\begin{tabular}{lllll|lllll}
55 & 45 & 35 & 25 & 15 & 61 & 62 & 63 & 64 & 65 \\
\hline 85 & 84 & 83 & 82 & 81 & 71 & 72 & 73 & 74 & 75
\end{tabular}

This should be:

\begin{tabular}{lllll|lllll}
55 & 54 & 53 & 52 & 51 & 61 & 62 & 63 & 64 & 65 \\
\hline 85 & 84 & 83 & 82 & 81 & 71 & 72 & 73 & 74 & 75
\end{tabular}

8. Page 140 Figure 8.1 is just one of many photographs which is not close up enough! I cannot see the ends of the instruments in enough detail to identify them in the flesh. Another is page 213 - forcep identification would not be aided by these photographs.

9. Page 188 extraction aftercare. There is no mention of abstaining from alcohol (may cause bleeding), smoking (may cause localised ostietis/dry socket), spicy food (aggravates socket), or excessive exercise for at least 12 hours (may cause bleeding). This is important information otherwise extraction patients find themselves back at the surgery within a day or so in agony or bleeding!

I am aware that the syllabus is different for NVQ, but surely charting symbols and post extraction information do not change. With reference to the 'easy to recognise colour diagrams and photographs' I found the images so small I couldn't identify instruments - a must for the spotter tests!

Needless to say this book has never been used and continues to collect dust at the back of a cupboard. A letter outlining the errors was sent to the publishers who then sent it to the authors. No further correspondence was received.

The best book for any dental nurse is H. Levison's Textbook for dental nurses. I relied on this book when studying for my National Certificate ... and passed.

Libby Morris, Dental nurse/receptionist, Llanidloes

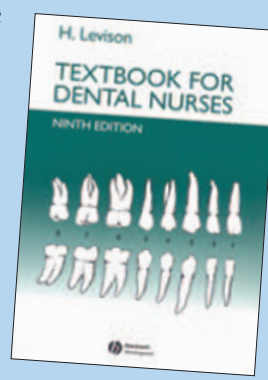

Please turn over for a response from PasTest Ltd... 